\title{
Sobre um caso de nevrite leprosa
}

Observação apresentada á cadeira de Clinica Neurologica da Faculdade de Medicina de Dau o pelo doutorando José Campos.

A. A., 58 annos de idade, sexo masculino, nacionalidade italiana, raça latina, cor branca, viuvo, lavrador até a idade de 32 annos ,em sua terra natal, actualmente sorveteiro, residente á rua Visconde de Parnahyba, 216.

\section{ANAMNESE}

\section{QUEIXA ACTUALMENTE}

Perda lenta e progressiva da força muscular de ambos os membros, superiores e inferiores, com adormecimento das extremidades. Perturbações para o lado da visão.

\section{HISTORIA DA MOLESTIA ACTUAL}

Ha tres annos que vem soffrendo da molestia que accusa. A principio forte queimação (sic) em todos os membros inferiores, que o obrigou a procurar este Hospital, internando-se na enfermaria de pelle, onde ficou por espaço de 6 mezes; vendo que o seu estado se agravava, em nada melhorando com a medicação que lhe estava sendo administrada (fricção de pomada em ambos os membros inferiores) de lá se retirou procurando o Hospital Umberto Primo, onde permaneceu por espaço de um anno. Passados 4 mezes depois da sua sahida do Hospital Humberto Primo, com relativa melhora, verificou que aos poucos ia perdendo a sua força muscular, cançando-se ao menor esforço, a ponto de muitas vezes, com a dor e a fraqueza nas pernas, ser obrigado a parar de andar. Ao mesmo tempo notou que a sua vista se perturbava, não podendo distinguir mais perfeitamente nada, a distancia, e a suas mãos, menos ageis, se apresentavam com os dedos em forma de garras e adormecidos.

\section{ANTECEDENTES PESSOAES}

Das molestias exhantematicas, peculiares á infancia nada sabe contar. Sempre foi muito forte e sadio, nunca tendo tido molestia 
alguma. Bebida em demasia. - 1 litro a litro e meio por dia, de vinho tinto. Fuma regularmente desde a idade de 14 annos. Nega antecedentes venereo-syphiliticos.

\section{ANTECEDENTES FAMILIARES E HEREDITARIOS}

Casou com a idade de 30 annos. Tem 5 filhos, todos fortes e sadios. Sua mulher teve dez abortos. Esta soffrera um ataque, ha questão de um anno atraz, ficando hemiplegica. Em principios deste anno, soffreu um segundo ataque, ficando em estado de coma apopletico, vindo a fallecer, dez dias depois.

INTERROGATORIO SOBRE OS DIFFERENTES APPARELHOS

Cabeça:

Sofria cephaleias intensas, até dois annos atraz.

Olhos:

A não ser de trez annos para cá, nunca soffreu perturbações da vista.

Actualmente queixa-se de falta da visão. Tem notado que as suas pestanas e sobrancelhas tem cahido.

Ouvido e Nariz:

Nada accusa para o lado destes orgãos.

Cardio respiratorio:

Sente constantemente, pontadas no peito, do lado esquerdo, proximo á ponta do coração; accusa palpitações, dyspnéa e insomnia.

Gastro intestinal:

Bom appetite; alimenta-se perfeitamente. Digestão difficil com dores que cessam algum tempo depois das refeições. Não accusa vomitos, hematemese nem melena. Não soffre de hemorhoides nem diarrhéas.

Genito urinario:

Nada accusa par ao lado deste apparelho.

Neuro muscular:

Sempre foi nervoso exaltando-se á menor contrariedade. Não accusa insonia, vertigens nem convulsões. A sua força muscular, de tres annos para cá tem diminuido progressivamente.

EXAME PHYSICO

Cabeça:

Rosto cheio, facies não caracteristica. Não apresenta nenhuma deformidade tanto para o lado do rosto, cranio, como orelhas. Ligeiramente careca, com falta de pellos nas sobrancelhas e quasi que falta completa das pestanas. Apresenta umas manchas na face, correspondendo mais ou menos a região encoberta pelos pellos, prin- 
oipalmente á direita, onde existe uma de forma triangular, de cor amarellada, apresentando uns pontos esbranquiçados, vindo desde a apophyse zygomatica até o bordo de maxilar inferior. Ao nivel destas manchas os pelles da barba são mais raros. $\mathrm{Na}$ face e posterior do pescoço, nota-se a presença de uma cicatriz transversal, larga, superficial, ao que o doente conta ter sido de uma ulcera curada.

O nariz não é augmentado de volume, mas apresenta uns nodulos de coloração amarellada e avermelhada.

Thorax:

Revella na parte posterior do espaço inter-escapular direito, uma mancha arredondada de cor avermelhada. $\mathrm{Na}$ parte anterior do thorax notam-se manchas puntiformes, disseminadas em diversos pontos. Na parte media da face anterior do thorax, correspondendo a parte inferior da região esternal, existe uma cicatriz vertical, proveniente de uma intervenção cirurgica soffrida pelo doente, ha dois annos atraz.

\section{Membros superiores:}

Notam-se principalmente na face de extensão, outras manchas puntiformes e na parte posterior e superior dos ante-braços, manchas extensas arroxeadas.

Em ambas as mãos, estando os membros em extensão, notam-se garras cubitaes mais pronunciada a esquerda que a direita. Os espaços inter-osseos de ambas as mãos, principalmente os dois ultimos apresentam-se escavados, com a eminencia hypotenar achatada.

A' direita os dedos estão em abducção. Não flexão em nenhum dos dedos e nem abducção do pollegar. A esquerda é mais pronunciada a atrophia dos musculos innervados pelo cubital; nota-se aqui garra no dedo minimo com flexão das duas ultimas phalanges sobre a primeira, e extensão desta ultima sobre o metacarpiano. Existe nitida abducção do dedo pollegar. A garra do dedo minimo é irredutivel pela ankylose da articulação da phalange com a phalanginha. Em ambos os ante-braços existe ligeiro gráo de atrophia. Em ambas os lados ha grande espessamento do nervo cubital na gott. epitrocleo olecraniana.

Abdomem:

Ventre ligeiramente abaulado e distendido. $\mathrm{Na}$ parte posterior do tronco, logo abaixo da região renal, á direita, notam-se manchas desseminadas, de volume e extensão variadas e de cor parda escura.

Membros inferiores:

Em ambos os membros inferiores notam-se tambem numerosas manchas de extensão muito variavel, sendo umas de cor amarellada e outras arroxeadas.

$\mathrm{Na}$ face anterior de ambas as pernas, notam-se grandes manchas arroxeadas que segundo o doente são devidas a traumatismo. 
Os pés se apresentam cyanoticos. Ligeiro edema em ambos os membros inferiores, principalmente nos pés.

Systema osseo e muscular:

A não ser a ankylose do dedo minimo e as atrophias indicadas, systema osseo e muscular em perfeito desenvolvimento.

Tecido adiposo:

Paniculo adiposo e systema piloso bem desenvolvido, a não ser ao nivel de algumas manchas, cujos pellos fazem falta.

\section{REFLEXOS}

Reflexos profundos:

Reflexos profundos dos membros inferiores presente e normaes.

No membro superior e reflexo tricipital, bicipital, estyloradial, estão presentes, mas muito diminuidos em ambos os lados.

Reflexos superficiaes:

Cutaneos-abdominaes, presentes. Cremasterinos ausentes. Reflexo cutaneo plantar em flexão.

Reflexos pupillares:

Anisocoria, com myose a esquerda. Reflexos pupillares a luz e accomodação, presentes. Pupillas são mal contornadas. Força muscular diminuida em ambas as mãos. No resto dos membros, superiores e inferiores, força muscular conservada.

Paralysia com atrophia dos interosseos (mão em garra por acommettimento do nervo cubital).

Sensibilidades:

SENSIBILIDADE AO TACTO

A sensibilidade ao tacto se encontra presente em todo o corpo.

SENSIBILIDADE DOLOROSA

A sensibilidade dolorosa se encontra bastante diminuida nas pernas e abolida na face interna de ambos os pés, inclusive os arteIhos que se apresentam arroxeados. Nos membros superiores, abolida nas mãos e sensivelmente diminuida na face cubital do ante-braço, em toda a sua extensão. No restante do corpo, se encontra presente e normal, a não ser ao nivel de algumas manchas, onde se acham abolidas.

\section{SENSIBILIDADE THERMICA}

$\mathrm{O}$ doente, do joelho para baixo não percebe nitidamente o frio $\mathrm{e}$ o quente, havendo atrazo de resposta, e confusão de sensaçöes. $\mathrm{O}$ mesmo se dá no ante-braço e mãos de ambos os lados. 


\section{EXAME DOS APPARELHOS}

Nada encontramos digno de nota, nos apparelhos respiratorio, circulatorio, digestivo e genito-urinario, que interessassem ao nosso caso.

\section{EXAMES DE LABORATORIO:}

O exame do muco nasal duas vezes, em epochas differentes, para a pesquisa do bacillo de Hansen, resultou negativo.

A escarificação ao nivel de placas anesthesicas, para a pesquisa no soro, do bacillo, de Hansen resultou igualmente negativio.

\section{DIAGNOSTICO:}

LEPRA (nevrite leprosa e lepra maculo anesthesica).

\section{THERAPEUTICA :}

No estado actual dos nossos conhecimentos pode-se affirmar, sem receio de contradicção que a lepra se deixa influenciar favoravelmente por multiplos methodos therapeuticos, sem se deixar, entretanto, abater por qualquer que tenha, contra ella, acção especifica. No inicio da molestia e mesmo em seu periodo avançado, todos os medicamentos dão resultado, ainda mais porque o mal se caracteriza por "poussées" de reacções a que se seguem phenomenos de amortecimento, que poderão ser tomados como resultado da therapeutica.

Em todo o caso, o oleo de chalmoougra deve ser prescripto de modo constante.

\section{DISCUSSÃo:}

Temos que discutir no estabelecimento do diagnostico do nosso caso as tres hypotheses seguintes: a lepra, a syringo-myelia e molestia de Morvan.

- A lepra, a syringo-myelia e a molestia de Morvan, apresentam analogias tão grandes, que certos autores as tem identificado como sendo uma só.

Entretanto, se a lepra, na sua forma anesthesica se traduz, por perturbações sensitivas, motoras e trophicas, comparaveis áquellas da syringo-myelia, não quer isso dizer, não existem certos caracteres differenciaes entre uma e outra entidade morbida. Assim é que as perturbações sensitivas de origem sensitiva na lepra, revestem uma disposição troncular (em placas, em fitas, segmentarias), mas nunca radicular e raramente ellas são dissociadas. De outro lado as perturbações trophicas na lepra interessam symetricamente os dedos da mão e muitas vezes do pé, e via de regra são mais grave e mutilantes que na syringo-myelia; demais na syringo-myelia a symetria é 
rara e o compromettimento dos dedos do pé é excepcional. Ainda como elemento de diagnostico differencial devemos nos referir á ausencia dos exageros dos reflexos e da cypho-escoliose, á existencia de nevromas sobre o trajecto dos nervos, da myotrophia dos membros inferiores, da diplegia facial, da queda das sobrancelhas e pestanas, de manchas erythemathosas sobre a pelle, que são signaes que nos levam a pensar em lepra.

A doença descripta por Morvan constituida pela coexistencia do panaricio analgesico com atrophia muscular e anesthesia da mão pode simular a syringo-myelia nas formas que se iniciam por perturbações trophicas. Todavia o ataque habitual da sensibilidade tactil na doença de Morvan, o grande numero de panaricios analgesicos encontrados por Morvan, permittindo pensar que se trate de uma nevrite ou infecciosa, com predominancia local, nos leva a separar esse estado morbido da syringo-myelia, mas não exclue a possibilidade de se tratar da lepra como agente responsavel pelo mal de Morvan.

Pelos dados acima e caracteres differenciaes estabelecidos podemos apezar da negatividade das pesquizas de laboratorio para o bacillo de Hansen, affirmar seja o nosso observado portador de lepra.

Este diagnostico que poderá ser mais seguro com a pratica da biopsia e das reacções do desvio do complemento, foi feito em vista dos caracteres clinicos presentes a saber:

a) espessamento do nervo cubital

b) atrophia muscular e mão em garra (vide photographia)

c) manchas anesthesicas disseminadas pelo tegumento

d) perda de cabellos dos cilios e sobmancelhas

e) profunda perturbação da sensibilidade a dor, e notadas perturbações trophicas (vaso-motoras).

Por isso tudo affirmamos tratar-se de lepra.

\section{LABORATORIO PAULISTA DE BIOLOGIA}

\section{GYMNOSAN}

\section{Ether ethylico dos acidos gordos do oleo de Chaulmoogra}

O mais moderno tra'amento da lepra.

Usa-se 1 injecção de 1 c. c. cada 3 dias, hypodermicamente. 


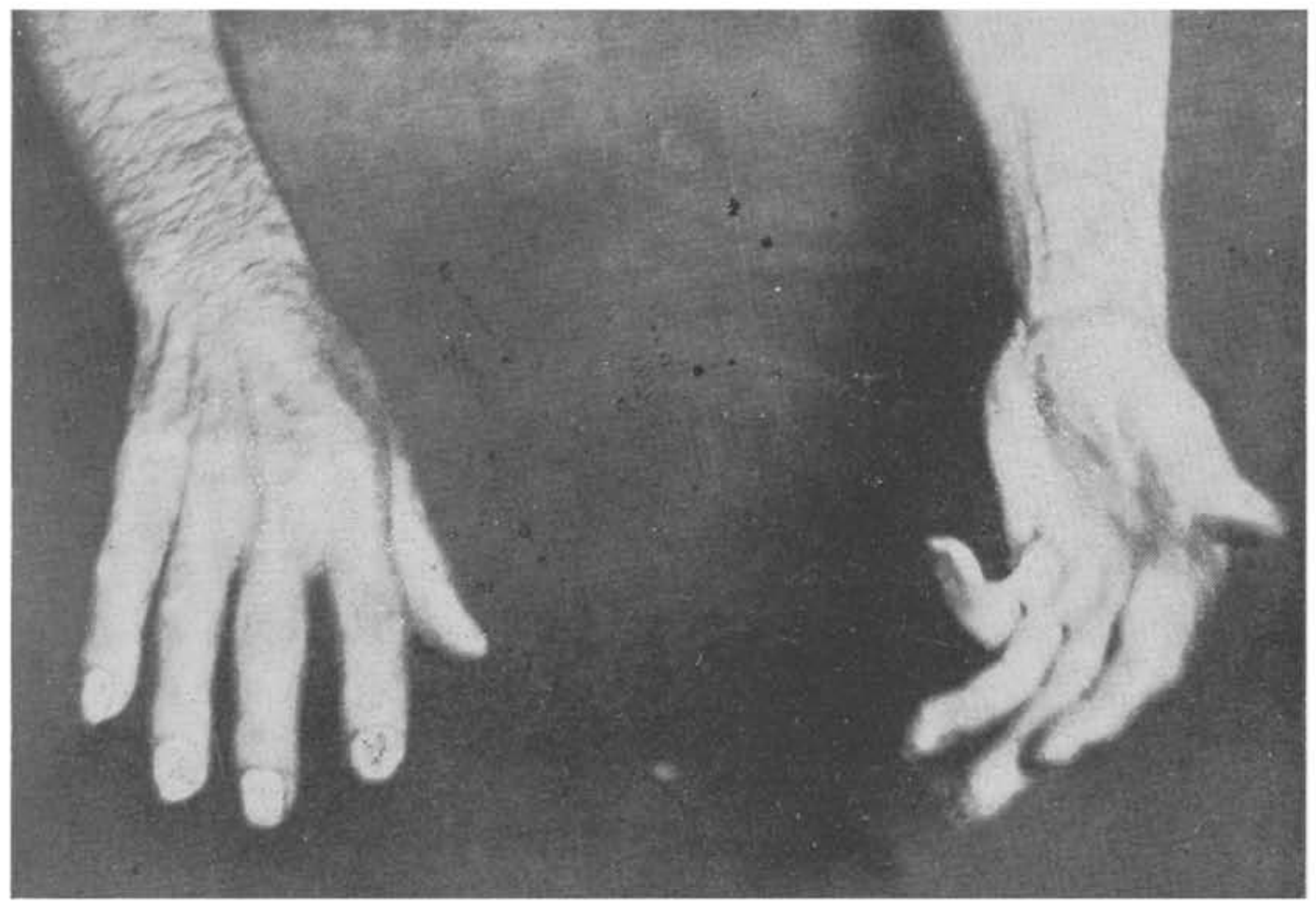

Photographia mostrando as garras cubitaes, mais pronunCIADAS á ESQUerda QUE á DIREITA. OS ESPAÇOS INTEROSSEOS DE AMBAS AS MÃOS APRESENTAM-SE EXCAVADOS, COM A EMINENCIA HYPOTHENAR ACHATADA. Á DIREITA OS DEDOS ESTÃO EM ABDUCÇÃO; NÃO HA FLEXÃO EM NENHUM DOS DEDOS, NEM ABDUCÇÃO Do pollegar. Á esquerda É maIs pronunciada a ATrophia dos MUSCULOS INNERVADOS PELO CUBITAL; NOTA-SE GARRA DO DEDO MINIMO COM FLEXÃO DAS DUAS ULTIMAS PHALANGES SOBRE A PRIMEIRA E EXTENSÃO DESTA SOBRE O METACARPIO; EXISTE NITIDA ABDUCÇÃO DO POLLEGAR; A GARRA DO MINIMO É IRREDUCTIVEL POR ANKYLOSE. 